OPEN ACCESS

Edited by:

Dragan D. Micic

University of Belgrade, Serbia

Reviewed by:

Tricia Mei Mei Tan,

Imperial College London,

United Kingdom

Bruno Ramos-Molina,

Instituto de Investigación Biomédica

de Málaga (IBIMA), Spain

${ }^{*}$ Correspondence:

Angelo Di Vincenzo

divincenzoang@gmail.com

Specialty section

This article was submitted to

Obesity,

a section of the journal

Frontiers in Endocrinology

Received: 12 August 2018 Accepted: 06 December 2018 Published: 18 December 2018

Citation:

Di Vincenzo A, Busetto L, Vettor $R$ and Rossato M (2018) Obesity, Male Reproductive Function and Bariatric Surgery. Front. Endocrinol. 9:769. doi: 10.3389/fendo.2018.00769

\section{Obesity, Male Reproductive Function and Bariatric Surgery}

\author{
Angelo Di Vincenzo *, Luca Busetto, Roberto Vettor and Marco Rossato \\ Department of Medicine-DIMED, Center for the Study and Integrated Management of Obesity, Clinica Medica 3, \\ University-Hospital of Padova, Padova, Italy
}

Overweight and obesity are associated with several chronic complications, such as type 2 diabetes, arterial hypertension and atherosclerotic cardiovascular diseases, with relevant consequences for patients and public health systems. Reproductive function abnormalities, such as obesity-related secondary hypogonadism, erectile dysfunction and infertility, represent other abnormalities negatively affecting the quality of life of men suffering from obesity but, despite their high prevalence, these are often understated because of a general lack of awareness in clinical practice. Obesity and gonadal function are closely related, with obesity being associated with hypogonadism that is reversed by body weight reduction thus ameliorating reproductive and sexual health. Clinical studies specifically evaluating the impact of non-surgical weight loss on testosterone levels sometimes showed conflicting results, whereas extensive literature has demonstrated that weight loss after bariatric surgery is correlated with an increase in testosterone levels greater than that obtained with only lifestyle interventions, suggesting the role of surgery also for the treatment of hypogonadism in obese male. However, studies concerning the consequences of bariatric surgery on overall reproductive function in the male, including also sexual activity and fertility, are limited and data regarding long-term effects are lacking. Here we present a brief review summarizing the evidence regarding the interplay between obesity and reproductive abnormalities in the obese male, together with the role of bariatric surgery for the treatment of these complications, describing both the positive effects and the limitations of this procedure.

Keywords: obesity, testosterone, male hypogonadism, sexual function, erectile function, fertility, weight loss, bariatric surgery

\section{INTRODUCTION}

Appropriate management of patients with obesity needs a complete evaluation and treatment of each associated cardiovascular, metabolic and endocrine disturbance $(1,2)$. However, despite their high prevalence, reproductive function abnormalities are often undertreated in obese population compared to the cardio-metabolic comorbidities.

As for the other well-known complications of obesity, bariatric surgery seems to be the most effective treatment for reproductive abnormalities in obese males, frequently ensuring the complete normalization of testosterone levels, along with long-term weight maintenance, although the evidence of the effects on fertility and sexual activity is still scarce. The mechanisms linking hypothalamic-pituitary-gonadal axis, obesity and metabolic surgery are far from being completely understood, and surgical weight loss sometimes is not sufficient to ameliorate sexual function 
and, consequently, the quality of life. To this regard, we performed a comprehensive review of the available literature to summarize the actual evidence concerning the interplay between obesity and reproductive abnormalities and the role of bariatric surgery for the treatment of these complications, analyzing the possible underlying mechanisms but also exposing its limitations.

\section{OBESITY AND MALE REPRODUCTIVE FUNCTION}

Obesity is associated with a constellation of endocrine disturbances and, among them, reproductive function abnormalities are now recognized as relevant clinical problems in subjects with obesity. It is well-known that in women obesity is associated with menstrual irregularity, reduced fertility, higher prevalence of polycystic ovary syndrome (PCOS) (3), but also with gestational diabetes, pregnancy-related hypertension and increased risk of obesity in the offspring. In men with obesity, hypogonadism, erectile dysfunction (ED) and reduced fertility represent complications seriously affecting patient quality of life and health (4-8). Thus, their control may represent another therapeutic target in these subjects.

\section{Sex Hormones in Obesity}

Abnormal levels of sex hormones are often observed in men with obesity. Male-obesity secondary hypogonadism (MOSH) represents an endocrine dysfunction with a reported prevalence of about $45 \%$ in moderate-severe obesity (9). Furthermore, it has been reported that the prevalence of hypogonadism in obese male is higher in the presence of type 2 diabetes (T2D) $(10,11)$.

$\mathrm{MOSH}$ is characterized by different signs and symptoms, such as sexual dysfunction, depression, fatigue, decreased lean body mass and also reduced mineral bone density, which further impact on patients' health. Hormonal abnormalities characterizing $\mathrm{MOSH}$ are represented by decreased free and total testosterone plasma levels, together with decreased sex-hormone binding globulin (SHBG) and increased estradiol plasma levels. Usually, in this situation, gonadotropins are inappropriately low or normal, resembling a hypogonadotropic hypogonadism, but in a less percentage of patients with metabolic syndrome higher gonadotropin levels may be observed (12).

Low testosterone and high estradiol plasma levels are common features of the metabolic syndrome, and an inverse relationship between body mass index (BMI) or waist circumference and testosterone plasma levels over all age group of patients has been extensively shown (13-15). To this respect, it is largely accepted that the development of MOSH depends on adipose tissue expansion and adipocyte dysfunction. An elevated waist circumference is the expression of increased visceral adipose tissue (VAT), which can result in an enhancement of in-situ aromatase activity (16). This enzyme is highly expressed in adipose tissue and is thought to be responsible for the increased conversion of circulating testosterone to $17 \beta$-estradiol in men with obesity, favoring the development of secondary hypogonadism. At the same time, this condition leads to a vicious cycle in which low testosterone contributes to maintaining high body weight and excessive abdominal fat deposition (17). In fact, testosterone may be responsible for several metabolic effects influencing also adipocyte biology by interacting with the androgen receptor that is expressed in adipose tissue, thus preventing visceral fat accumulation and improving insulin sensitivity. Furthermore, testosterone might exert a protective role from gluco-toxicity damage on pancreatic $\beta$-cells, due to an antioxidant activity on pancreatic islets preventing the $\beta$-cell apoptosis (18) or to a modulation of the renin-angiotensinaldosterone pathway by reducing the expression of angiotensin II type 1 receptor (AGTR1), as previously reported (19). These effects may be lost with the reduction of circulating testosterone levels, and this may explain the relationship between low testosterone plasma levels and development of insulin resistance and T2D. This could be the case not only for men with MOSH, but also for age-related late-onset hypogonadism as well as in men undergoing androgen suppression for prostate cancer. Sex hormones balance has a crucial role in energy homeostasis, energy expenditure and then body mass composition. To this respect, it is interesting to note that the effects of testosterone on adipose tissue seem mediated also by skeletal muscle. In fact, in vitro experimental studies have shown that testosterone may interact with androgen-receptor to promote myogenic commitment of pluripotent mesenchymal cell and inhibit adipogenic differentiation via Wnt signaling $(20,21)$. Furthermore, increased serum levels of leptin and proinflammatory cytokines produced by inflamed adipose tissue (such as IL-6 and TNF- $\alpha$ ) might have an additional suppressive effect on reproductive function. In particular, leptin has been hypothesized to negatively affect testicular steroidogenesis acting both at central and peripheral level, diminishing the pulse amplitude of luteinizing hormone releasing hormone (LHRH)/luteinizing hormone (LH) or through the activation of its receptor present on Leydig cell $(22,23)$.

It is also relevant to note that metabolic complications associated with obesity, T2D in particular, further affect gonadal function and testosterone levels. Different studies have reported that low testosterone levels predict the development of T2D in men and are inversely correlated with dyslipidemia and blood pressure levels (24-27). In agreement with this observation, it has been reported that higher testosterone levels are associated with a lower risk of T2D (28). Finally, androgen deprivation treatment in patients with prostate cancer is also related to an increased risk for the development of T2D (29). On the other hand, testosterone replacement therapy has been shown to be effective in weight loss and glucose homeostasis in patients with hypogonadism and metabolic syndrome.

Different mechanisms have been suggested to explain how insulin resistance, T2D and hypogonadism are interconnected in males. The effect of hyperinsulinemia on lowering testosterone concentrations has been evaluated many years ago $(30,31)$, showing that insulin acts both at central level, impairing the activity of gonadotropin releasing-hormone $(\mathrm{GnRH})$ secreting neurons, and peripherally, where it may suppress SHBG synthesis (32), LH signaling (33), or modulate Leydig cell activity (34). The association becomes even more complex when associated complications develop. Obstructive sleep apnoea is a 
condition characterized by low circulating testosterone levels, but testosterone replacement in these patients has been associated with a worsening of clinical symptoms (35). Furthermore, it has been reported that the relationship between testosterone plasma levels and non-alcoholic fatty liver disease (NAFLD) shows a gender difference: low testosterone levels are independently associated with NAFLD in men and post-menopausal women (36), whereas testosterone levels are inversely associated with NAFLD in women (37), and increased levels of testosterone in PCOS patients are observed in association with $\operatorname{NAFLD}(38,39)$.

Thus, the treatment of hypogonadism in patients with obesity, T2D or metabolic syndrome should consider also to the management of associated metabolic complications. To this respect testosterone replacement therapy in hypogonadal obese men has been previously suggested. Different studies have confirmed that testosterone replacement therapy in obese men leads not only to the amelioration of sexual activity, but also to the reduction of body weight, improved insulin sensitivity and reduction of other well-known cardiovascular risk factors, such as cholesterol plasma levels and inflammatory markers (40-43).

Taken together, this evidence shows a bidirectional interconnection between testosterone deficiency and metabolic diseases, a relation becoming further intriguing considering that low testosterone plasma levels have been recognized as an additional risk factor for cardiovascular disease $(44,45)$, and thus hypogonadism may account as another clinical complication of obesity (Figure 1). So, the identification of $\mathrm{MOSH}$ in obese subjects is strongly recommended for a complete risk stratification.

\section{Sexual Activity, Erectile Function, and Fertility in Obesity}

Obesity has a relevant negative impact not only on sex hormones levels but also on the overall sexual performance. Furthermore, according to some observations, adipose tissue expansion seems to influence also gonadal activity and spermatogenesis, leading to the reduction of fertility in obese males. BMI seems to be independently correlated with erectile function, with a high prevalence of overweight and obesity in patients suffering for ED. In comparison with normal BMI subjects, patients with a BMI higher than $28,7 \mathrm{Kg} / \mathrm{m}^{2}$ show a $30 \%$ higher risk of ED (46), and it has been reported that patients with obesity waiting for bariatric surgery show a higher probability to suffer from ED with respect to those following non-surgical weight loss programs (47). In addition, in patients with ED, the presence of obesity and associated metabolic complications seems to affect further the severity of the disease, even reducing the responsiveness to phosphodiesterase 5 (PDE5) inhibitors (largely used for ED treatment) in subjects with higher BMI levels (48). Apart from the effect of MOSH and abnormal sex hormones levels, vascular and microvascular abnormalities associated with VAT expansion and chronic low-grade systemic inflammation, may represent another possible link between obesity and ED. In fact, obesity is associated with several clinical markers of subclinical atherosclerosis, such as endothelial dysfunction and impaired activity of endothelial nitric oxide, which may be at least in part responsible for the development of ED in this population. With these pathophysiological mechanisms in mind, the overlap between obesity and ED seems to represent a point of connection between adipose tissue expansion and vascular complications. Then, the presence of ED in obese subjects may account for an increased cardiovascular risk.

On the contrary, conflicting results have been observed in studies evaluating the correlation between BMI and sperm parameters, such as sperm concentration and total sperm count, although it is generally accepted that men with obesity seem to have a higher risk of azoospermia or oligozoospermia (49-51). The mechanisms by which obesity may influence fertility are complex and heterogeneous. Hyperinsulinemia and hyperleptinemia, classical features of obesity, may have a direct effect on spermatogenesis because of oxidative stress and inflammatory state, with loss of sperm DNA integrity $(52,53)$. Obesity might act centrally as for hypogonadism, influencing the hypothalamus-pituitary-testis axis. Furthermore, it is also possible that increased VAT may be responsible for an increased scrotal temperature which could impair testicular function.

The different treatments of obesity, such as lifestyle modification, pharmacological and surgical therapy are associated with an improvement of the different obesityassociated diseases along with weight loss, and body weight reduction appears to be effective also for MOSH. The different studies on the effects of behavioral modifications on male obese reproductive function have shown discordant results (54-56). On the contrary, a huge amount of literature has demonstrated that surgical weight loss is associated with an increase in testosterone plasma levels higher than that obtained with lifestyle modifications alone, probably reflecting the correlation between the severity of obesity and the grade of gonadal activity impairment. In fact, after surgical weight loss, an increase of testosterone plasma levels is observed in patients with $\mathrm{MOSH}$, with a magnitude of androgen rise greater in those patients losing more weight (57), often leading to completely revert hypogonadism (58). However, at the moment, the effects of bariatric surgery on reproductive function in obese males remain not entirely known, and their explanation might be relevant to define future therapeutic options in obese males with MOSH and/or other reproductive abnormalities with contraindication to bariatric surgery.

\section{ROLE OF SURGICAL WEIGHT LOSS ON REPRODUCTIVE FUNCTION IN MALE OBESITY}

Considering their prevalence, obesity-associated gonadal dysfunctions may represent an important target for bariatric surgery. A recent meta-analysis has shown that, in patients undergoing bariatric surgery, PCOS was present in $36 \%$ of women whether MOSH was present in $64 \%$ of men, with a high percentage of remission after surgery (96\% for PCOS, $87 \%$ for MOSH) (59). Below we present a brief description of the effects of bariatric surgery on male sex hormones plasma levels, ED and semen quality. 


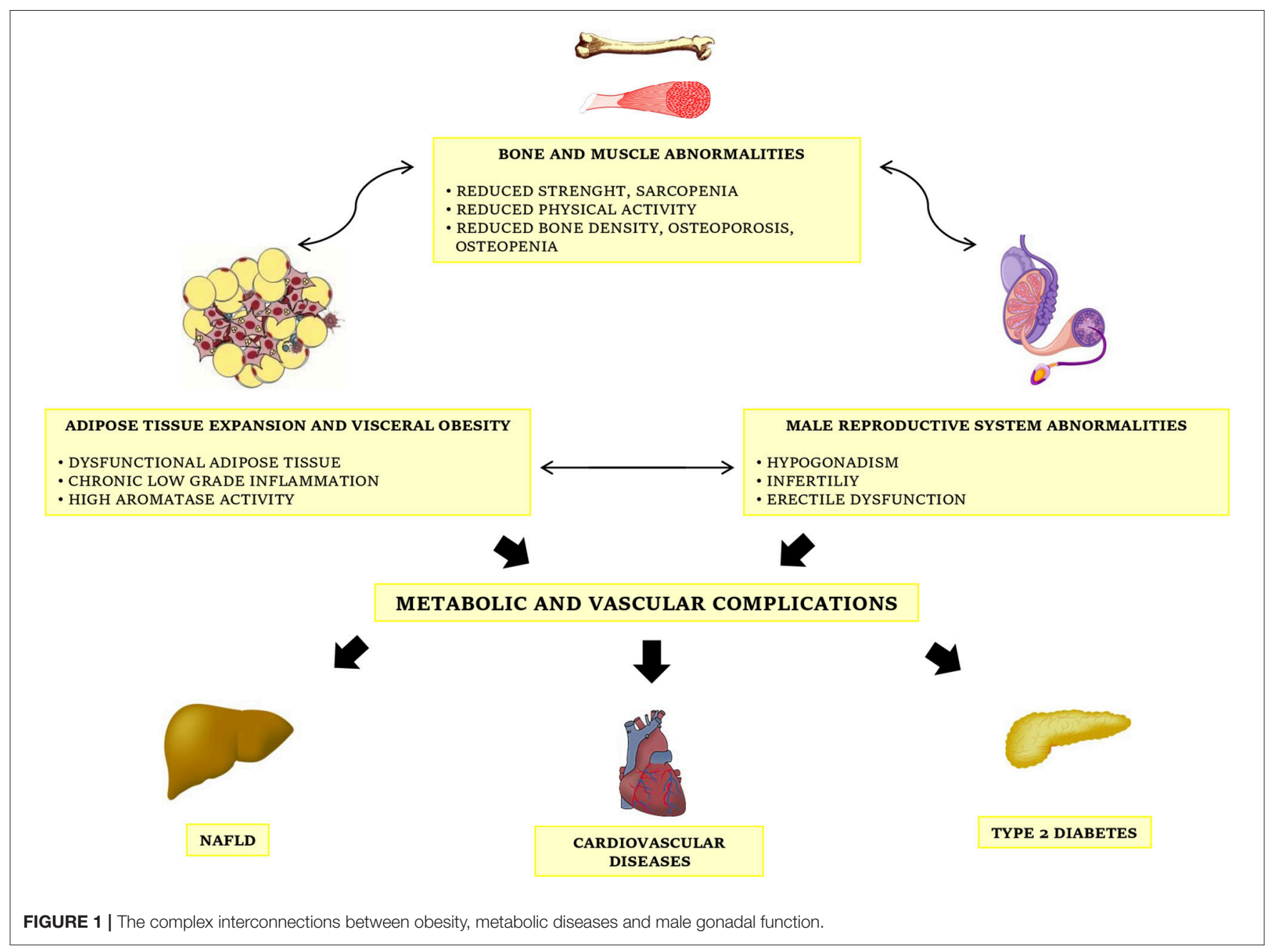

\section{Bariatric Surgery and Sex Hormones Plasma Levels}

As previously mentioned, exogenous testosterone has been proven to be effective in hypogonadal obese men also in the amelioration of anthropometric and metabolic parameters $(40-43,60)$, and it could be a helpful treatment strategy in this population. However, androgen replacement therapy still has a reduced diffusion among physicians, probably because of apprehension for the possible adverse effects, such as exacerbation of OSA, worsening in lower urinary tract symptoms, and the risk of neoplastic prostate disease. In addition, exogenous testosterone may exert a negative feedback on releasing of gonadotropins which may further influence the fertility status. Weight loss has a great role in increasing testosterone levels, and a rapid weight loss obtained with lifestyle modifications has shown a beneficial effect in subjects with obesity. Niskanen et al. demonstrated that after a 9-week verylow-calorie diet there was an increase in SHBG and total testosterone plasma levels that were maintained also during weight control period (61). The results of a recent study evaluating the effects of medical treatment (dietary intervention and physical exercise) with the aim of $10 \%$ weight loss, confirmed a significant increase of total testosterone and a reduction of 17$\beta$ estradiol plasma levels after weight loss (62). Other studies evaluating the effects of calorie restriction on testosterone plasma levels reported conflicting results, while more promising results have been obtained from studies associating diet and testosterone replacement therapy (63).

On the other hand bariatric surgery is linked to greater effects on reproductive hormones abnormality in the male. Extensive literature has shown the positive effect of bariatric surgery on $\mathrm{MOSH}$ and this effect is irrespective of the type of surgery. Calderón et al demonstrated that significant postoperative outcomes on weight loss, HOMA index, fasting glucose, waist circumference, but also total and free testosterone plasma levels were not different between different bariatric surgery procedures such as gastric bypass, adjustable gastric banding or sleeve gastrectomy $(64,65)$. A limitation of these studies is represented by the heterogeneity of surgical procedures, sometimes considering the effects both of restrictive and malabsorptive surgery, which might be responsible for a relevant bias. However, after surgical weight reduction, many different 
studies have shown that the increase in total testosterone plasma levels is directly associated with amelioration of metabolic parameters whatever the surgical technique utilized, such as biliopancreatic diversion, vertical banded gastroplasty, and Roux-en-Y gastric by-pass (RYGB) (66-68), confirming the existence of an intricate hypothalamic-gonadal-adipocyte axis.

A positive effect of bariatric surgery on sex hormones plasma levels is commonly observed after a mid- or long-term follow up, but it can also present a rapid onset, already at 1 month from sleeve gastrectomy or RYGB $(69,70)$. With the maintenance of weight loss and appropriate weight control, the effects of bariatric surgery on sex hormones levels may be observed also for longer times. Pham et al recently performed an ancillary analysis from STAMPEDE trial, evaluating free and total testosterone levels 5 years after sleeve gastrectomy or RYGB in obese men with T2D. Patients who underwent bariatric surgery showed a higher increase in total and free testosterone levels with respect to medical patients in the long period ( 84.1 vs. 9.6\%, $p=0.008$, and 47.4 vs. $-2.2 \%, p=0.013)$, without significant changes in estradiol levels (71). Interestingly the increase in free testosterone observed in this study was associated with a reduction in body weight, high sensitivity-C reactive protein and leptin plasma levels, but not with an improvement in glycemic control. These results may be explained by the development of more severe abnormalities of gonadal function occurring when obesity coexists with other metabolic diseases, showing that adipose tissue dysfunction and systemic inflammation further influence gonadal activity in addition to insulin resistance and glucose metabolism alterations.

To this regard, the effects of bariatric surgery on gonadal function may be directly linked to body weight loss and, in particular, to visceral fat mass reduction. A recent study evaluating the correlation between sex hormones plasma levels and VAT (measured with magnetic resonance imaging), confirmed that visceral fat area is the main parameter associated with testosterone levels at baseline and, in addition, showed that after bariatric surgery visceral fat area is negatively associated with the increase in total testosterone plasma levels (72). VAT is well known to represent the most relevant risk factor associated with cardio-metabolic risk in patients with obesity Furthermore it probably accounts also for the development of hypogonadism in obese male, since abnormalities of adipocyte function in VAT result in negative effects on endocrine system, given that the imbalanced production of adipokines and inflammatory mediators such as leptin, IL-6, and TNF may directly influence testicular activity in vitro $(23,73)$, but evidence is lacking in vivo. Moreover, the reduction in VAT, that expresses higher aromatase activity with respect to the subcutaneous adipose tissue (SAT), may result in a reduced conversion of circulating testosterone leading to the reduction of estradiol and increase in testosterone plasma levels.

However, there are other clinical circumstances which may influence the amplitude of the effects of metabolic surgery on sex hormones recovery beyond weight loss per se. Age represents a relevant determinant for amelioration of MOSH, probably because younger subjects could have a greater response of testicular function to hypothalamic-pituitary hormones (in particular to the increase of LH levels) (74) or conversely because of an abnormal hypothalamic responsiveness to circulating sex hormones (75). To this respect, another limitation of the studies evaluating the post-surgical recovery of hypogonadism is represented by the age of studied subjects, who are usually young men when at the time of bariatric surgery.

The improvement of testosterone plasma levels may favor a condition in which the restoration of muscle strength and resistance leads to increased physical activity, amelioration of obesity-related sarcopenia and positive effects also on osteopenia and articular function, globally contributing to weight loss maintenance (76). Considering the experimental evidence regarding the influence of bone on testicular function (77), metabolic surgery may present these intriguing additional effects. To this regard, Samavat et al observed that osteocalcin, a bone hormone produced by osteoblasts, which seems to play a role on the regulation of testis function, increased after bariatric surgery, and this increase was parallel with the rising in free testosterone levels (78).

\section{Bariatric Surgery and Erectile Function}

A healthy lifestyle can preserve or restore erectile function in men, in particular in men with obesity who are at higher risk for ED because of associated metabolic and neuro-vascular abnormalities. Esposito et al showed the beneficial effects of lifestyle changes (reduced caloric intake and increased physical activity) on $\mathrm{ED}$ in subjects with obesity in a randomized controlled trial in which the intervention group, receiving detailed advice about how to achieve a loss of $10 \%$ or more by, obtained a significant improvement in the International Index of Erectile Function (IIEF) score (79). The beneficial effects of a moderate (10\%) weight loss on sexual function have been confirmed by others (80).

As demonstrated by a recent meta-analysis, bariatric surgery leads to a significant improvement of ED as assessed by IIEF (81). ED is commonly reported by patients with severe obesity in the pre-operative period, but it may be improved by surgical induced weight loss. Dallal et al. showed that gastric bypass may revert also a severe sexual dysfunction (evaluated in this study with the Brief Male Sexual Function Inventory), with the excess of weight loss independently predicting the entity of the improvement (82). As for the increase in total testosterone plasma levels, bariatric surgery seems to guarantee an early amelioration of erectile function at six but also 1 month from surgery (83-85).

Surgical weight loss can ameliorate erectile dysfunction, as evaluated by IIEF questionnaire, probably through a modification in sex hormones plasma levels, in particular increasing follicle-stimulating hormone (FSH), total and free testosterone (86). Nonetheless it is also possible that bariatric surgery acts with a more complex mechanism. In a retrospective study conducted on Chinese obese patients with ED, Kun et al demonstrated the beneficial effects of RYGB on erectile function and showed the correlation between IIEF score and arterial integrity (both cavernosal and carotid artery, evaluated with Doppler ultrasound), irrespective of baseline BMI (87). In fact, the amplitude of the improvement of sexual function on IIEF seems to be independent of the increase of sex hormones plasma 
levels, confirming a more profound alteration of sexual function in obese patients which is not associated with testosterone activity alone. In a prospective observational case-series study, Mora et al observed, using a multivariate regression analysis, that variations of $\mathrm{BMI}$ and not hormonal and metabolic factors were independent predictors of IIEF score improvement at 1 year from bariatric surgery (88).

However, there are no univocal data about long term effects of surgical weight loss, and bariatric surgery does not always guarantee a complete normalization of erectile function. This observation is probably linked to the weight regain or to the persistence of metabolic abnormalities $(89,90)$, or also to psychological issues. A retrospective study by Ranasinghe et al evaluating a male obese population undergoing laparoscopic gastric banding showed an improvement of IIEF score without overall sexual function improvement: in particular, erectile index and orgasmic function worsened when adjusted for time (91). On the contrary, other studies evaluating pre- and post-surgical sexuality in male obese subjects, described positive effects of surgical weight loss, pointing also to the role of psychological issues on overall sexual activity $(92,93)$.

\section{Bariatric Surgery and Semen Quality}

Beyond the sex hormonal status and related clinical symptoms, bariatric surgery may potentially be associated not only with the improvement of reproductive hormones and related clinical symptoms but also with amelioration of semen parameters possibly resulting in improved fertility. Samavat et al analyzed the effects of RYGB on semen quality after 6 months from the procedure in a cohort study. They observed an increased sperm count, motility and ejaculate volume after treatment although not reaching the statistical significance. In addition, they also showed a reduction in sperm DNA fragmentation and semen IL-8, unconventional parameters of semen quality (94). Increase in total testosterone plasma levels may be partially responsible for these modifications, but these results also confirm the hypothesis regarding a deep, complex effect of obesity on reproduction, testicular activity and fertility in men, which may be reversed only partially by weight loss. Obesity may affect directly the biochemical activity of the testis, as demonstrated by lower levels of inhibin B observed in obese men, and bariatric surgery can potentially improve also this parameter (95). On the contrary, a retrospective study by Legro et al showed no amelioration in semen parameters of obese men that underwent gastric bypass (96). A previous prospective randomized study of Reis et al comparing surgical procedure and medical followup showed similar results: gastric by-pass obtained a significant increase in IIEF score, total and free testosterone levels in the

\section{REFERENCES}

1. Bray GA, Frühbeck G, Ryan DH, Wilding JP. Management of obesity. Lancet (2016) 387:1947-56. doi: 10.1016/S0140-6736(16)0 0271-3

2. Garvey WT, Mechanick JI, Brett EM, Garber AJ, Hurley DL, Jastreboff $\mathrm{AM}$, et al. American association of clinical endocrinologists and american college of endocrinology comprehensive clinical practice guidelines for intervention group, but did not affect sperm quality (97). In a prospective study of El Bardisi et al evaluating effects of sleeve gastrectomy on semen parameters, semen quality was not affected by surgical weight loss except for subgroups of men with pre-existing azoospermia or oligospermia (98). Some reports have also described the possibility that bariatric surgery may negatively influence sperm parameters, probably because of nutritional deficiency and induction of a systemic catabolic state with consequent accumulation of toxic metabolites (99101). However, taken together, these data are relatively too weak to definitely clarify the situation, and more controlled studies in large populations are needed regarding this topic.

\section{CONCLUSION}

Bariatric surgery seems to be effective to improve free and total testosterone plasma levels in obese men, even if more evidence is needed about changes of other hormones such as gonadotropins and adrenal sex steroids. In addition, while testosterone plasma levels improvement is maintained for a long-term, restored erectile function seems not to be a durable effect, even if increased semen quality is not guaranteed after metabolic surgery. These conditions may be explained by the complex pathophysiology of reproductive function abnormalities occurring in men with obesity. In particular, adipose tissue expansion and consequent biochemical activity impairment (cytokines and adipokines production, increase peripheral androgens aromatization) may be responsible for reduced levels of testosterone while different and even more complex mechanisms, involving not only sex hormones levels but also neuro-vascular abnormalities and gonadal specific alterations, could be responsible for erectile dysfunction and infertility. To this regard, metabolic surgery may present some limitations; however, with respect to nonsurgical weight loss, bariatric surgery remains the most effective treatment for a rapid improvement of global sexual activity and hypogonadism, so it could be considered as a relevant option for severely obese hypogonadal males.

\section{AUTHOR CONTRIBUTIONS}

DVA and RM equally wrote the article. VR and BL revised the paper.

\section{ACKNOWLEDGMENTS}

We used for our figure images from: Pixabay.com and Freepik.com-designed by Brgfx.

medical care of patients with obesity. Endocr Pract. (2016) 22:842-84. doi: 10.4158/EP161356.ESGL

3. Lim SS, Davies MJ, Norman RJ, Moran LJ. Overweight, obesity and central obesity in women with polycystic ovary syndrome: a systematic review and meta-analysis. Hum Reprod Update (2012) 18:618-37. doi: 10.1093/humupd/dms030

4. Hafner RJ, Watts JM, Rogers J. Quality of life after gastric bypass for morbid obesity. Int J Obes. (1991) 15:555-60. 
5. Moore RH, Sarwer DB, Lavenberg JA, Lane IB, Evans JL, Volger S, et al. Relationship between sexual function and quality of life in obese persons seeking weight reduction. Obesity (2013) 21:1966-74. doi: 10.1002/oby.20398

6. Poggiogalle E, Di Lazzaro L, Pinto A, Migliaccio S, Lenzi A, Donini LM. Health-related quality of life and quality of sexual life in obese subjects. Int $J$ Endocrinol. (2014) 2014:847871. doi: 10.1155/2014/847871

7. Dong JY, Zhang YH, Qin LQ. Erectile dysfunction and risk of cardiovascular disease: meta-analysis of prospective cohort studies. J Am Coll Cardiol. (2011) 58:1378-85. doi: 10.1016/j.jacc.2011.06.024

8. Eisenberg ML, Li S, Behr B, Cullen MR, Galusha D, Lamb DJ, et al. Semen quality, infertility and mortality in the USA. Hum Reprod. (2014) 29:1567-74. doi: 10.1093/humrep/deu106

9. Calderón B, Gómez-Martín JM, Vega-Piñero B, Martín-Hidalgo A, Galindo J, Luque-Ramírez M, et al. Prevalence of male secondary hypogonadism in moderate to severe obesity and its relationship with insulin resistance and excess body weight. Andrology (2016) 4:62-7. doi: 10.1111/andr.12135

10. Dandona P, Dhindsa S. Update: hypogonadotropic hypogonadism in type 2 diabetes and obesity. J Clin Endocrinol Metab. (2011) 96:2643-51. doi: 10.1210/jc.2010-2724

11. Chughtai B, Lee RK, Te AE, Kaplan SA. Metabolic syndrome and sexual dysfunction. Curr Opin Urol. (2011) 21:514-8. doi: 10.1097/MOU.0b013e32834b8681

12. Dhindsa S, Furlanetto R, Vora M, Ghanim H, Chaudhuri A, Dandona P. Low estradiol concentrations in men with subnormal testosterone concentrations and type 2 diabetes. Diabetes Care (2011) 34:1854-9. doi: 10.2337/dc11-0208

13. Stanworth RD, Jones TH. Testosterone in obesity, metabolic syndrome and type 2 diabetes. Front Horm Res. (2009) 37:74-90. doi: 10.1159/000176046

14. Makhsida N, Shah J, Yan G, Fisch H, Shabsigh R. Hypogonadism and metabolic syndrome: implications for testosterone therapy. J Urol. (2005) 174:827-34. doi: 10.1097/01.ju.0000169490.78443.59

15. Svartberg J. Epidemiology: testosterone and the metabolic syndrome. Int $J$ Impot Res. (2007) 19:124-8. doi: 10.1038/sj.ijir.3901499

16. Wake DJ, Strand M, Rask E, Westerbacka J, Livingstone DE, Soderberg $\mathrm{S}$, et al. Intra-adipose sex steroid metabolism and body fat distribution in idiopathic human obesity. Clin Endocrinol. (2007) 66:440-6. doi: 10.1111/j.1365-2265.2007.02755.x

17. Cohen PG. Aromatase, adiposity, aging and disease. The hypogonadalmetabolic-atherogenic-disease and aging connection. Med Hypotheses (2001) 56:702-8. doi: 10.1054/mehy.2000.1169

18. Hanchang W, Semprasert N, Limjindaporn T, Yenchitsomanus PT, Kooptiwut S. Testosterone protects against glucotoxicity-induced apoptosis of pancreatic $\beta$-cells. (INS-1) and male mouse pancreatic islets. Endocrinology (2013) 154:4058-67. doi: 10.1210/en.2013-1351

19. Kooptiwut S, Hanchang W, Semprasert N, Junking M, Limjindaporn T, Yenchitsomanus PT. Testosterone reduces AGTR1 expression to prevent $\beta$ cell and islet apoptosis from glucotoxicity. J Endocrinol. (2015) 224:215-24. doi: 10.1530/JOE-14-0397

20. Singh R, Artaza JN, Taylor WE, Gonzalez-Cadavid NF, Bhasin S. Androgens stimulate myogenic differentiation and inhibit adipogenesis in $\mathrm{C} 3 \mathrm{H}$ $10 \mathrm{~T} 1 / 2$ pluripotent cells through an androgen receptor-mediated pathway. Endocrinology (2003) 144:5081-8. doi: 10.1210/en.2003-0741

21. Singh R, Artaza JN, Taylor WE, Braga M, Yuan X, Gonzalez-Cadavid NF, et al. Testosterone inhibits adipogenic differentiation in 3T3-L1 cells: nuclear translocation of androgen receptor complex with beta-catenin and T-cell factor 4 may bypass canonical Wnt signaling to downregulate adipogenic transcription factors. Endocrinology (2006) 147:141-54. doi: 10.1210/en.2004-1649

22. Martin LJ. Implications of adiponectin in linking metabolism to testicular function. Endocrine (2014) 46:16-28. doi: 10.1007/s12020-0130102-0

23. Isidori AM, Caprio M, Strollo F, Moretti C, Frajese G, Isidori A, et al. Leptin and androgens in male obesity: evidence for leptin contribution to reduced androgen levels. J Clin Endocrinol Metab. (1999) 84:3673-80. doi: $10.1210 /$ jc. 84.10 .3673

24. Svartberg J, von Mühlen D, Schirmer H, Barrett-Connor E, Sundfjord J, Jorde R. Association of endogenous testosterone with blood pressure and left ventricular mass in men. The Tromsø Study. Eur J Endocrinol. (2004) 150:65-71. doi: 10.1530/eje.0.1500065
25. Traish AM, Feeley RJ, Guay A. Mechanisms of obesity and related pathologies: androgen deficiency and endothelial dysfunction may be the link between obesity and erectile dysfunction. FEBS J. (2009) 276:5755-67. doi: 10.1111/j.1742-4658.2009.07305.x

26. Stellato RK, Feldman HA, Hamdy O, Horton ES, McKinlay JB. Testosterone, sex hormone-binding globulin, and the development of type 2 diabetes in middle-aged men: prospective results from the Massachusetts male aging study. Diabetes Care (2000) 23:490-4. doi: 10.2337/diacare. 23.4.490

27. Haffner SM, Shaten J, Stern MP, Smith GD, Kuller L. Low levels of sex hormone-binding globulin and testosterone predict the development of non-insulin-dependent diabetes mellitus in men. MRFIT research group multiple risk factor intervention trial. Am J Epidemiol. (1996) 143:889-97. doi: 10.1093/oxfordjournals.aje.a008832

28. Ding EL, Song Y, Malik VS, Liu S. Sex differences of endogenous sex hormones and risk of type 2 diabetes: a systematic review and meta-analysis. JAMA (2006) 295:1288-99. doi: 10.1001/jama.295.11.1288

29. Keating NL, O'Malley AJ, Freedland SJ, Smith MR. Diabetes and cardiovascular disease during androgen deprivation therapy: observational study of veterans with prostate cancer. J Natl Cancer Inst. (2010) 102:39-46. doi: 10.1093/jnci/djp404

30. Pasquali R, Macor C, Vicennati V, Novo F, De lasio R, Mesini P, et al. Effects of acute hyperinsulinemia on testosterone serum concentrations in adult obese and normal-weight men. Metabolism (1997) 46:526-9. doi: 10.1016/S0026-0495(97)90189-X

31. Pasquali R, Casimirri F, De lasio R, Mesini P, Boschi S, Chierici R, et al. Insulin regulates testosterone and sex hormone-binding globulin concentrations in adult normal weight and obese men. J Clin Endocrinol Metab. (1995) 80:654-658.

32. Tsai EC, Matsumoto AM, Fujimoto WY, Boyko EJ. Association of bioavailable, free, and total testosterone with insulin resistance: influence of sex hormone-binding globulin and body fat. Diabetes Care (2004) 27:861-8. doi: $10.2337 /$ diacare.27.4.861

33. Benitez A, Perez Diaz J. Effect of streptozotocin-diabetes and insulin treatment on regulation of Leydig cell function in the rat. Horm Metab Res. (1985) 17:5-7. doi: 10.1055/s-2007-1013433

34. Pitteloud N, Hardin M, Dwyer AA, Valassi E, Yialamas M, Elahi D, et al. Increasing insulin resistance is associated with a decrease in Leydig cell testosterone secretion in men. J Clin Endocrinol Metab. (2005) 90:2636-41. doi: 10.1210/jc.2004-2190

35. Cole AP, Hanske J, Jiang W, Kwon NK, Lipsitz SR, Kathrins M, et al. Impact of testosterone replacement therapy on thromboembolism, heart disease and obstructive sleep apnoea in men. BJU Int. (2018) 121:811-8. doi: 10.1111/bju.14149

36. Yim JY, Kim J, Kim D, Ahmed A. Serum testosterone and non-alcoholic fatty liver disease in men and women in the US. Liver Int. (2018) 38:2051-59. doi: 10.1111/liv.13735

37. Jaruvongvanich V, Sanguankeo A, Riangwiwat T, Upala S. Testosterone, sex hormone-binding globulin and nonalcoholic fatty liver disease: a systematic review and meta-analysis. Ann Hepatol. (2017) 16:382-94. doi: 10.5604/01.3001.0009.8593

38. Rocha ALL, Faria LC, Guimarães TCM, Moreira GV, Cândido AL, Couto $\mathrm{CA}$, et al. Non-alcoholic fatty liver disease in women with polycystic ovary syndrome: systematic review and meta-analysis. J Endocrinol Invest. (2017) 40:1279-88. doi: 10.1007/s40618-017-0708-9

39. Kumarendran B, O’Reilly MW, Manolopoulos KN, Toulis KA, Gokhale KM, Sitch AJ, et al. Polycystic ovary syndrome, androgen excess, and the risk of nonalcoholic fatty liver disease in women: a longitudinal study based on a United Kingdom primary care database. PLoS Med. (2018) 15:e1002542. doi: 10.1371/journal.pmed.1002542

40. Saad F, Haider A, Doros G, Traish A. Long-term treatment of hypogonadal men with testosterone produces substantial and sustained weight loss. Obesity (2013) 21:1975-81. doi: 10.1002/oby.20407

41. Haider A, Yassin A, Doros G, Saad F. Effects of long-term testosterone therapy on patients with 'diabesity': results of observational studies of pooled analyses in obese hypogonadal men with type 2 diabetes. Int J Endocrinol. (2014) 2014:683515. doi: 10.1155/2014/ 683515 
42. Haider A, Yassin A, Doros G, Traish AM, Saad F. Reductions of weight and waist size in 362 hypogonadal men with obesity grades I to III under longterm treatment with testosterone undecanoate. (TU): observational data from two registry studies. In: Abstract (SAT-0940) Presented at the Endocrine Society's 96th Annual Meeting (2014).

43. Yassin A, Doros G. Testosterone therapy in hypogonadal men results in sustained and clinically meaningful weight loss. Clin Obes. (2013) 3:73-83. doi: $10.1111 /$ cob. 12022

44. Vikan T, Schirmer H, Njølstad I, Svartberg J. Endogenous sex hormones and the prospective associations with cardiovascular disease and mortality in men. The Tromso Study. Eur J Endocrinol. (2009) 161:435-42.doi: 10.1530/EJE-09-0284

45. Yeap BB, Hyde Z, Almeida OP, Norman PE, Chubb SA, Jamrozik K, et al. Lower testosterone levels predict incident stroke and transient ischemic attacks in older men. J Clin Endocrinol Metab. (2009) 94:2353-9. doi: $10.1210 /$ jc. 2008-2416

46. Bacon CG, Mittleman MA, Kawachi I, Giovannucci E, Glasser DB, Rimm EB. Sexual function in men older than 50 years of age: results from the health professionals follow-up study. Ann Intern Med. (2003) 139:161-8. doi: 10.7326/0003-4819-139-3-200308050-00005

47. Sarwer DB, Spitzer JC, Wadden TA, Rosen RC, Mitchell JE, Lancaster K, et al. Sexual functioning and sex hormones in persons with extreme obesity and seeking surgical and nonsurgical weight loss. Surg Obes Relat Dis. (2013) 9:997-1007. doi: 10.1016/j.soard.2013.07.003

48. Demir O, Akgul K, Akar Z, Cakmak O, Ozdemir I, Bolukbasi A, et al. Association between severity of lower urinary tract symptoms, erectile dysfunction and metabolic syndrome. Aging Male. (2009) 12:29-34. doi: 10.1080/13685530902777425

49. Andersen JM, Herning H, Aschim EL, Hjelmesæth J, Mala T, Hanevik HI, et al. Body mass index is associated with impaired semen characteristics and reduced levels of anti-müllerian hormone across a wide weight range. PLoS ONE (2015) 10:e0130210. doi: 10.1371/journal.pone.0130210

50. MacDonald AA, Herbison GP, Showell M, Farquhar CM. The impact of body mass index on semen parameters and reproductive hormones in human males: a systematic review with meta-analysis. Hum Reprod Update (2010) 16:293-311. doi: 10.1093/humupd/dmp047

51. Sermondade N, Faure C, Fezeu L, Shayeb AG, Bonde JP, Jensen TK, et al. BMI in relation to sperm count: an updated systematic review and collaborative meta-analysis. Hum Reprod Update (2013) 19:221-31. doi: 10.1093/humupd/dms050

52. Leisegang K, Bouic PJ, Menkveld R, Henkel RR. Obesity is associated with increased seminal insulin and leptin alongside reduced fertility parameters in a controlled male cohort. Reprod Biol Endocrinol. (2014) 12:34. doi: 10.1186/1477-7827-12-34

53. Agarwal A, Virk G, Ong C, du Plessis SS. Effect of oxidative stress on male reproduction. World J Mens Health (2014) 32:1-17. doi: 10.5534/wjmh.2014.32.1.1

54. Armamento-Villareal R, Aguirre LE, Qualls C, Villareal DT. Effect of lifestyle intervention on the hormonal profile of frail, obese older men. J Nutr Health Aging (2016) 20:334-40. doi: 10.1007/s12603-016-0698-x

55. Kaukua J, Pekkarinen T, Sane T, Mustajoki P. Sex hormones and sexual function in obese men losing weight. Obes Res. (2003) 11:689-94. doi: $10.1038 /$ oby. 2003.98

56. Leenen R, van der Kooy K, Seidell JC, Deurenberg P, Koppeschaar HP. Visceral fat accumulation in relation to sex hormones in obese men and women undergoing weight loss therapy. J Clin Endocrinol Metab. (1994) 78:1515-20.

57. Pellitero S, Olaizola I, Alastrue A, Martínez E, Granada ML, Balibrea $\mathrm{JM}$, et al. Hypogonadotropic hypogonadism in morbidly obese males is reversed after bariatric surgery. Obes Surg. (2012) 22:1835-42. doi: $10.1007 /$ s11695-012-0734-9

58. Samavat J, Facchiano E, Lucchese M, Forti G, Mannucci E, Maggi $\mathrm{M}$, et al. Hypogonadism as an additional indication for bariatric surgery in male morbid obesity? Eur J Endocrinol. (2014) 171:555-60. doi: 10.1530/EJE-14-0596

59. Escobar-Morreale HF, Santacruz E, Luque-Ramírez M, Botella Carretero JI. Prevalence of 'obesity-associated gonadal dysfunction' in severely obese men and women and its resolution after bariatric surgery: a systematic review and meta-analysis. Hum Reprod Update (2017) 23:390408. doi: 10.1093/humupd/dmx012

60. Saad F, Yassin A, Doros G, Haider A. Effects of long-term treatment with testosterone on weight and waist size in 411 hypogonadal men with obesity classes I-III: observational data from two registry studies. Int J Obes. (2016) 40:162-70. doi: 10.1038/ijo.2015.139

61. Niskanen L, Laaksonen DE, Punnonen K, Mustajoki P, Kaukua J, Rissanen A. Changes in sex hormone-binding globulin and testosterone during weight loss and weight maintenance in abdominally obese men with the metabolic syndrome. Diabetes Obes Metab. (2004) 6:208-15. doi: 10.1111/j.1462-8902.2004.00335.x

62. De Lorenzo A, Noce A, Moriconi E, Rampello T, Marrone G, Di Daniele N, et al. MOSH Syndrome. (Male Obesity Secondary Hypogonadism): clinical assessment and possible therapeutic approaches. Nutrients (2018) 10: E474. doi: 10.3390/nu10040474

63. Heufelder AE, Saad F, Bunck MC, Gooren L. Fifty-two-week treatment with diet and exercise plus transdermal testosterone reverses the metabolic syndrome and improves glycemic control in men with newly diagnosed type 2 diabetes and subnormal plasma testosterone. J Androl. (2009) 30:726-33. doi: 10.2164/jandrol.108.007005

64. Calderón B, Galdón A, Calañas A, Peromingo R, Galindo J, García-Moreno $\mathrm{F}$, et al. Effects of bariatric surgery on male obesity-associated secondary hypogonadism: comparison of laparoscopic gastric bypass with restrictive procedures. Obes Surg. (2014) 24:1686-92. doi: 10.1007/s11695-014-1233-y

65. Botella-Carretero JI, Balsa JA, Gómez-Martin JM, Peromingo R, Huerta L, Carrasco M, et al. Circulating free testosterone in obese men after bariatric surgery increases in parallel with insulin sensitivity. $J$ Endocrinol Invest. (2013) 36:227-32. doi: 10.3275/8469

66. Alagna S, Cossu ML, Gallo P, Tilocca PL, Pileri P, Alagna G, et al. Biliopancreatic diversion: long-term effects on gonadal function in severely obese men. Surg Obes Relat Dis. (2006) 2:82-6. doi: 10.1016/j.soard.2006.01.005

67. Bastounis EA, Karayiannakis AJ, Syrigos K, Zbar A, Makri GG, Alexiou D. Sex hormone changes in morbidly obese patients after vertical banded gastroplasty. Eur Surg Res. (1998) 30:43-7. doi: 10.1159/000008556

68. Hammoud A, Gibson M, Hunt SC, Adams TD, Carrell DT, Kolotkin RL, et al. Effect of Roux-en-Y gastric bypass surgery on the sex steroids and quality of life in obese men. J Clin Endocrinol Metab. (2009) 94:1329-32. doi: 10.1210/jc.2008-1598

69. Boonchaya-Anant P, Laichuthai N, Suwannasrisuk P, Houngngam N, Udomsawaengsup S, Snabboon T. Changes in testosterone levels and sex hormone-binding globulin levels in extremely obese men after bariatric surgery. Int J Endocrinol. (2016) 2016:1416503. doi: 10.1155/2016/1416503

70. Di Vincenzo A, Silvestrin V, Bertoli E, Foletto M, Pagano C, Fabris R, et al. Short-term effects of surgical weight loss after sleeve gastrectomy on sex steroids plasma levels and PSA concentration in men with severe obesity. Aging Male (2018). doi: 10.1080/13685538.2018.1528445. [Epub ahead of print].

71. Pham NH, Bena J, Bhatt DL, Kennedy L, Schauer PR, Kashyap SR. Increased free testosterone levels in men with uncontrolled type 2 diabetes five years after randomization to bariatric surgery. Obes Surg (2018) 28:277-80. doi: 10.1007/s11695-017-2881-5

72. Liu F, Tu Y, Zhang P, Bao Y, Han J, Jia W. Decreased visceral fat area correlates with improved total testosterone levels after Roux-en-Y gastric bypass in obese Chinese males with type 2 diabetes: a 12-month follow-up. Surg Obes Relat Dis. (2018) 14:462-8. doi: 10.1016/j.soard.2017. 11.009

73. Tena-Sempere M, Pinilla L, González LC, Diéguez C, Casanueva FF, Aguilar E. Leptin inhibits testosterone secretion from adult rat testis in vitro. $J$ Endocrinol. (1999) 161:211-8. doi: 10.1677/joe.0.1610211

74. Facchiano E, Scaringi S, Veltri M, Samavat J, Maggi M, Forti G, et al. Age as a predictive factor of testosterone improvement in male patients after bariatric surgery: preliminary results of a monocentric prospective study. Obes Surg. (2013) 23:167-72. doi: 10.1007/s11695-012-0753-6

75. Luconi M, Samavat J, Seghieri G, Iannuzzi G, Lucchese M, Rotella C, et al. Determinants of testosterone recovery after bariatric surgery: is it only a matter of reduction of body mass index? Fertil Steril. (2013) 99:1872-9.e1. doi: 10.1016/j.fertnstert.2013.02.039 
76. Neunhaeuserer D, Gasperetti A, Savalla F, Gobbo S, Bullo V, Bergamin $\mathrm{M}$, et al. Functional evaluation in obese patients before and after sleeve gastrectomy. Obes Surg. (2017) 27:3230-9. doi: 10.1007/s11695-017-2763-x

77. Liao M, Guo X, Yu X, Pang G, Zhang S, Li J, et al. (2013). Role of metabolic factors in the association between osteocalcin and testosterone in Chinese men. J Clin Endocrinol Metab. 98:3463-9. 10.1210/jc.2013-1805.

78. Samavat J, Facchiano E, Cantini G, Di Franco A, Alpigiano G, Poli $\mathrm{G}$, et al. Osteocalcin increase after bariatric surgery predicts androgen recovery in hypogonadal obese males. Int J Obes (2014) 38:357-63. doi: 10.1038/ijo.2013.228

79. Esposito K, Giugliano F, Di Palo C, Giugliano G, Marfella R, D’Andrea F, et al. Effect of lifestyle changes on erectile dysfunction in obese men: a randomized controlled trial. JAMA (2004) 291:2978-2984. doi: 10.1001/jama.291.24.2978

80. Khoo J, Piantadosi C, Worthley S, Wittert GA. Effects of a low-energy diet on sexual function and lower urinary tract symptoms in obese men. Int J Obes. (2010) 34:1396-403 doi: 10.1038/ijo.2010.76

81. Glina FPA, de Freitas Barboza JW, Nunes VM, Glina S, Bernardo WM. What is the impact of bariatric surgery on erectile function? A systematic review and meta-analysis. Sex Med Rev. (2017) 5:393-402. doi: 10.1016/j.sxmr.2017.03.008

82. Dallal RM, Chernoff A, O'Leary MP, Smith JA, Braverman JD, Quebbemann BB. Sexual dysfunction is common in the morbidly obese male and improves after gastric bypass surgery. J Am Coll Surg. (2008) 207:859-64. doi: 10.1016/j.jamcollsurg.2008.08.006

83. Aleid M, Muneer A, Renshaw S, George J, Jenkinson AD, Adamo M, et al. Early effect of bariatric surgery on urogenital function in morbidly obese men. J Sex Med. (2017) 14:205-14. doi: 10.1016/j.jsxm.2016.12.004

84. Groutz A, Gordon D, Schachter P, Amir H, Shimonov M. Effects of bariatric surgery on male lower urinary tract symptoms and sexual function. Neurourol Urodyn. (2017) 36:636-9. doi: 10.1002/nau.22980

85. Efthymiou V, Hyphantis T, Karaivazoglou K, Gourzis P, Alexandrides TK, Kalfarentzos F, et al. The effect of bariatric surgery on patient HRQOL and sexual health during a 1-year postoperative period. Obes Surg. (2015) 25:310-8. doi: 10.1007/s11695-014-1384-x

86. Reis LO, Favaro WJ, Barreiro GC, de Oliveira LC, Chaim EA, Fregonesi A, et al. Erectile dysfunction and hormonal imbalance in morbidly obese male is reversed after gastric bypass surgery: a prospective randomized controlled trial. Int J Androl. (2010) 33:736-44. doi: 10.1111/j.1365-2605.2009. 01017.x

87. Kun L, Pin Z, Jianzhong D, Xiaodong H, Haoyong Y, Yuqian B, et al. Significant improvement of erectile function after Roux-en-Y gastric bypass surgery in obese Chinese men with erectile dysfunction. Obes Surg. (2015) 25:838-44. doi: 10.1007/s11695-014-1465-x

88. Mora M, Aranda GB, de Hollanda A, Flores L, Puig-Domingo M, Vidal J. Weight loss is a major contributor to improved sexual function after bariatric surgery. Surg Endosc. (2013) 27:3197-204. doi: 10.1007/s00464-0132890-y

89. Rosenblatt A, Faintuch J, Cecconello I. Sexual hormones and erectile function more than 6 years after bariatric surgery. Surg Obes Relat Dis. (2013) 9:636-40. doi: 10.1016/j.soard.2012.06.010

90. Sarwer DB, Spitzer JC, Wadden TA, Rosen RC, Mitchell JE, Lancaster K, et al. Sexual functioning and sex hormones in men who underwent bariatric surgery. Surg Obes Relat Dis. (2015) 11:643-51. doi: 10.1016/j.soard.2014.12.014

91. Ranasinghe WK, Wright T, Attia J, McElduff P, Doyle T, Bartholomew M, et al. Effects of bariatric surgery on urinary and sexual function. BJU Int. (2011) 107:88-94. doi: 10.1111/j.1464-410X.2010.09509.x

92. Kinzl JF, Trefalt E, Fiala M, Hotter A, Biebl W, Aigner F. Partnership, sexuality, and sexual disorders in morbidly obese women: consequences of weight loss after gastric banding. Obes Surg. (2001) 11:455-8. doi: 10.1381/096089201321209323

93. Camps MA, Zervos E, Goode S, Rosemurgy AS. Impact of bariatric surgery on body image perception and sexuality in morbidly obese patients and their partners. Obes Surg. (1996) 6:356-60. doi: 10.1381/096089296765556700

94. Samavat J, Cantini G, Lotti F, Di Franco A, Tamburrino L, Degl'Innocenti S, et al. (2018). Massive weight loss obtained by bariatric surgery affects semen quality in morbid male obesity: a preliminary prospective double-armed study. Obes Surg. 28:69-76. doi: 10.1007/s11695-017-2802-7

95. Globerman H, Shen-Orr Z, Karnieli E, Aloni Y, Charuzi I. Inhibin B in men with severe obesity and after weight reduction following gastroplasty. Endocr Res. (2005) 31:17-26. doi: 10.1080/07435800500228971

96. Legro RS, Kunselman AR, Meadows JW, Kesner JS, Krieg EF, Rogers AM, et al. Time-related increase in urinary testosterone levels and stable semen analysis parameters after bariatric surgery in men. Reprod Biomed Online (2015) 30:150-6. doi: 10.1016/j.rbmo.2014.10.014

97. Reis LO, Zani EL, Saad RD, Chaim EA, de Oliveira LC, Fregonesi A. Bariatric surgery does not interfere with sperm quality-a preliminary long-term study. Reprod Sci. (2012) 19:1057-62. doi: 10.1177/1933719112440747

98. El Bardisi H, Majzoub A, Arafa M, AlMalki A, Al Said S, Khalafalla K, et al. Effect of bariatric surgery on semen parameters and sex hormone concentrations: a prospective study. Reprod Biomed Online (2016) 33:60611. doi: 10.1016/j.rbmo.2016.08.008

99. Lazaros L, Hatzi E, Markoula S, Takenaka A, Sofikitis N, Zikopoulos $\mathrm{K}$, et al. Dramatic reduction in sperm parameters following bariatric surgery: report of two cases. Andrologia (2012) 44:428-32. doi: 10.1111/j.1439-0272.2012.01300.x

100. Sermondade N, Massin N, Boitrelle F, Pfeffer J, Eustache F, Sifer C, et al. Sperm parameters and male fertility after bariatric surgery: three case series. Reprod Biomed Online (2012) 24:206-10. doi: 10.1016/j.rbmo.2011.10.014

101. di Frega AS, Dale B, Di Matteo L, Wilding M. Secondary male factor infertility after Roux-en-Y gastric bypass for morbid obesity: case report. Hum Reprod. (2005) 20:997-8. doi: 10.1093/humrep/deh707

Conflict of Interest Statement: The authors declare that the research was conducted in the absence of any commercial or financial relationships that could be construed as a potential conflict of interest.

Copyright (C) 2018 Di Vincenzo, Busetto, Vettor and Rossato. This is an open-access article distributed under the terms of the Creative Commons Attribution License (CC $B Y)$. The use, distribution or reproduction in other forums is permitted, provided the original author(s) and the copyright owner(s) are credited and that the original publication in this journal is cited, in accordance with accepted academic practice. No use, distribution or reproduction is permitted which does not comply with these terms. 